\title{
Optimal Management of Acute Severe Ulcerative Colitis (ASUC): Challenges and Solutions
}

This article was published in the following Dove Press journal:

Clinical and Experimental Gastroenterology

\author{
Tom Holvoet ${ }^{1,2}$ \\ Triana Lobaton ${ }^{2}$ \\ Pieter Hindryckx ${ }^{2}$ \\ 'Department of Gastroenterology, AZ \\ Nikolaas, Sint-Niklaas, Belgium; \\ ${ }^{2}$ Department of Gastroenterology, \\ University Hospital Ghent, Ghent, \\ Belgium
}

\begin{abstract}
Acute severe colitis is a severe complication of ulcerative colitis, affecting approximately $20 \%$ of patients. For physicians, it remains a challenging condition to treat. Current treatment algorithms have diminished the mortality associated with acute severe ulcerative colitis (ASUC), but colectomy rates remain high (approximately 30\%) despite advances in therapy. Colectomy in ASUC is particularly associated with important postoperative complications and morbidity. In this review, reasons for the inability to improve care and avoid evolution to colectomy for ASUC are explored and solutions that might lead to a better management of the disease are investigated.
\end{abstract}

Keywords: acute severe colitis, ulcerative colitis, inflammatory bowel disease

\section{Introduction}

Ulcerative colitis is a common inflammatory disorder affecting mainly the colon and rectum, of which the pathophysiology is incompletely understood. ${ }^{1}$ Current paradigm dictates that the disease results from a dysregulated immune response induced by a complex interplay between host genetics, the intestinal microbiome and environmental factors (the so-called "expososome"), although the exact cause remains to be elucidated. ${ }^{1}$ Patients typically present with rectal bleeding, diarrhoea, tenesmus and pain in the lower abdomen, with peak incidences between 15-30 and 50-70 years of age. Over the past decades, ulcerative colitis has become a common condition in Western society with a prevalence of 1 in 200 but incidence rates are on the rise worldwide. ${ }^{2}$

In the majority of patients, inflammation is contained to the rectum and/or leftsided colon and runs a mild-to-moderate course with intermittent relapses. Twenty percent of patients, however, will develop at least one episode of severe colitis during their lifetime, requiring hospitalisation and accompanied by a significant human and economic burden. ${ }^{3,4}$ Acute severe colitis or (ASUC) is defined by the modified Truelove and Wits criteria that combine presence of bloody stools $\geq 6$ times a day with symptoms of systemic toxicity such as temperature $\geq 37.8$ $\mathrm{C}$, haemoglobin $<10.5 \mathrm{~g} / \mathrm{dL}$, erythrocyte sedimentation rate $<30 \mathrm{~mm} / \mathrm{h}$ and/or a pulse rate of $\geq 90 \mathrm{bpm}^{5}$

Treatment of ASUC is based on early recognition and rapid administration of intravenous corticosteroids. Patients need to be re-evaluated on day 3 with instalment of rescue treatment with infliximab or cyclosporin when there is no clinical or biochemical improvement. ${ }^{3}$ Cases refractory to medical treatment should be referred to a surgeon for colectomy in a timely manner. 
Surprisingly, despite recent therapeutic advances in inflammatory bowel disease, the incidence of ASUC has not diminished and although the colectomy rates have fallen in the last decade they remain high (approximately 30\%). ${ }^{6}$ In this review, we explore the challenges in diagnosing and treating ASUC that might explain this discrepancy and formulate possible solutions towards better care.

\section{Search Methodology}

A literature search for relevant studies (inception to 31 March 2020) was performed using MEDLINE, EMBASE and the Cochrane Library. Following search terms were used: acute severe colitis, severe ulcerative colitis, ASUC. Review articles and conference proceedings were also searched to identify additional studies.

\section{Challenges Associated with ASUC Management \\ Challenge I: Identifying Patients at Risk} Remains a Problem in Clinical Practise

Early diagnosis of ASUC is historically based on the Truelove and Witts' criteria (see Table 1) consisting of the presence of bloody stools $\geq 6$ times a day and at least one of the following signs of systemic toxicity: pulse rate $>90 \mathrm{bpm}$, temperature $>$ 37.8 , haemoglobin $<10.5 \mathrm{~g} / \mathrm{dl}$ or erythrocyte sedimentation rate $(\mathrm{ESR})>30 \mathrm{~mm} / \mathrm{h}$. Despite being 60 years old, they still remain the most sensitive criteria to define ASUC, although they must always be applied and considered in view of the circumstances and setting. ${ }^{7}$ Other indices like the clinical partial Mayo clinic score and the Montreal classification are less frequently used in clinical practise, however comparative studies for diagnosis of ASUC are not available.,

Predicting which patients are likely to fail initial treatment with corticosteroids is essential in the management

Table I Truelove and Witt's Criteria for Acute Severe Ulcerative Colitis

\begin{tabular}{|l|l|l|l|}
\hline Activity & Mild & Moderate & Severe \\
\hline Number of bloody stools a day & $<4$ & $4-6$ & $\geq 6$ \\
Pulse rate $(\mathrm{bpm})$ & Normal & Intermediate & $\geq 90$ \\
Temperature $\left({ }^{\circ} \mathrm{C}\right)$ & Afebrile & Subfebrile & $>37.8$ \\
Haemoglobin $(\mathrm{g} / \mathrm{dl})$ & $>I I$ & $10.5-\mathrm{II}$ & $<10.5$ \\
Erythrocyte sedimentation & Not & Not & $>30$ \\
rate $(\mathrm{ESR})(\mathrm{mm} / \mathrm{h})$ & elevated & elevated & \\
\hline
\end{tabular}

Notes: Adapted with permission form Truelove SC, Witts LJ. Cortisone in ulcerative colitis final report ona therapeutic trial. Br Med J. 1955;2(4947):I04I-1048. Copyright $\odot$ 1955, BMJ Publishing Group Ltd. ${ }^{5}$ of ASUC. This allows for early and multidisciplinary planning of medical and/or surgical rescue therapy. ${ }^{3,8}$ Several predictive indices have been developed but are infrequently used in clinical practise.

The Oxford or Travis criteria are based on a retrospective case series of 48 patients with ASUC and demonstrated that a stool frequency of $>8$ or a CRP level of more than $45 \mathrm{mg} / \mathrm{l}$ on day 3 of admission was associated with an $85 \%$ chance of requiring colectomy during the same admission (Table 2). The more complex Scottish or Ho index, developed in a retrospective case series of 167 ASUC patients, combines radiographic colon distention, albumin levels on admission and average number of daily stools over the first three days of admission to calculate an index score. A total of $\geq 4$ points on day 3 is associated with a sensitivity of $85 \%$ and specificity of $75 \%$ for failing IV corticosteroids. The Lindgren score uses similar covariates as the Oxford criteria (stool frequency per day $+0.14 \times \mathrm{CRP}(\mathrm{mg} / \mathrm{L}))$. The score was derived in a retrospective cohort of 97 patients and subsequently validated in a clinical trial, showing a sensitivity of $78 \%$ and specificity of $81 \%$ for predicting non-response.

Recent studies, however, have questioned the clinical applicability of some of these indices. In a follow-up study between 2013 and 2017, Moore et al investigated the accuracy of the Oxford criteria in the current therapeutic setting. Of the 80 patients admitted with ASUC, 33 fulfilled the Oxford criteria of which only 12 (36\%) eventually required a colectomy during the same admission. ${ }^{9}$

Other single predictors of treatment failure have been investigated in the past but none of these studies has provided a clear solution. Clinical follow-up of the stool frequency has been studied in a retrospective analysis of 189 ASUC cases in St. Marks hospital, UK and a stool frequency of $>12$ after $24 \mathrm{~h}$ of medical treatment was associated with a risk for colectomy of $55 \%$ during the same admission. ${ }^{10}$ In a prospective Italian study of 67 patients, a $<40 \%$ reduction in the number of stools was associated with corticosteroid failure. ${ }^{11}$ In clinical practise, however, following the exact number of bowel movements in acutely ill patients can be very challenging. ${ }^{3}$

Low albumin levels $(<30 \mathrm{~g} / \mathrm{L})$ at admission were found to be predictive of colectomy in $>40 \%$ of patients in the same retrospective St Marks series, although prospective studies could not confirm these findings. ${ }^{10}$ Combining low albumin levels $(<30 \mathrm{~g} / \mathrm{L})$ with elevated an CRP $(>50 \mathrm{mg} /$ L) and a severe score on endoscopic evaluation (the socalled ACE-index) predicted failure to corticosteroids in $78 \%$ of cases in a large retrospective study including 235 
Table 2 Predictive Indices for Corticosteroid Failure in Acute Severe Ulcerative Colitis

\begin{tabular}{|l|l|l|}
\hline Score & Criteria & $\begin{array}{l}\text { Probability of IV Corticosteroids } \\
\text { Failure }\end{array}$ \\
\hline $\begin{array}{l}\text { Travis or Oxford } \\
\text { criteria }\end{array}$ & $>8$ stools or CRP $>45 \mathrm{mg} / \mathrm{L}$ & $\begin{array}{l}\text { If any present on day } 3=85 \% \\
\text { probability of colectomy }\end{array}$ \\
\hline $\begin{array}{l}\text { Ho or Scottish } \\
\text { index }\end{array}$ & $\begin{array}{l}\text { Colonic dilatation }>5.5 \mathrm{~cm}=4 \text { points } \\
\text { Albumin }<3 \mathrm{~g} / \mathrm{dl} \text { on admission }=\text { I point } \\
\text { Average daily number of stools over first } 3 \text { days: }<4=0 \text { points; } 4-6=1 \text { points, } \\
6-9=2 \text { points; } \geq 9=4 \text { points }\end{array}$ & $\begin{array}{l}\geq 4 \text { points on day } 3=85 \% \text { probability of } \\
\text { non-response }\end{array}$ \\
\hline Lindgren score & Stool frequency per dag $+0.14 \times$ CRP $(\mathrm{mg} / \mathrm{L})$ & $\begin{array}{l}>8 \text { points on day } 3=72 \% \text { probability of } \\
\text { non-response }\end{array}$ \\
\hline
\end{tabular}

Note: Data from Gisbert et al. ${ }^{8}$

ASUC patients. ${ }^{12}$ Faecal calprotectin levels $>1922 \mu \mathrm{g} / \mathrm{g}$ were found to have a $97 \%$ specificity for colectomy in a Scottish prospective study including 90 ASUC patients, but this was accompanied by low sensitivity (24\%) limiting its clinical application. ${ }^{13}$ In another retrospective Chinese cohort of 71 ASUC patients, faecal calprotectin levels $>1672 \mu \mathrm{g} / \mathrm{g}$ on day 3 after colonoscopy predicted colectomy with a sensitivity of $80.2 \%$ and a specificity of $66.7 \% .{ }^{14}$ Elevated serum CRP levels at day $3(>9.9 \mathrm{mg} /$ dL) were also associated with steroid failure in a prospective paediatric cohort of 128 children. ${ }^{15}$ Elevated serum procalcitonin levels $(>0.10 \mu \mathrm{g} / \mathrm{L})$ were found to be a predictor for corticosteroid failure and colectomy in a retrospective study of 151 ASUC patients. ${ }^{16}$ Colonic microRNA expression profiles show promise as biomarker in ASUC. In a retrospective analysis in 47 patients, a combination of 5 colonic mucosal microRNAs could accurately predict treatment failure using a deep learning algorithm (AUC 0.82). ${ }^{17}$ Currently, serum albumin, CRP and fecal calprotectin are the most usable biochemical markers in clinical practise.

Endoscopic signs of severity include the presence of deep colonic ulcerations which are associated with a higher risk of corticosteroid failure and subsequent colectomy. ${ }^{3,8}$ Endoscopic indices can be useful in predicting treatment failure in ASUC. The Ulcerative Colitis Endoscopic Index of Severity (UCEIS), a composite score incorporating vascular pattern, bleeding and presence of erosions ranging, was investigated in a retrospective study of 89 patients with ASUC. Fifty percent of patients with an UCEIS of $\geq 5$ required rescue therapy with infliximab or cyclosporin, compared to $27 \%$ of patients with an UCEIS $<4$. When UCEIS was more than 7 , rescue therapy beyond corticosteroids was needed in almost all patients suggesting UCEIS $\geq 7$ as a decision threshold. ${ }^{18}$ As the UCEIS correlates better with therapeutic outcome it should be preferably used in ASUC compared to the classical Mayo score.

Lastly, plain abdominal radiography can also provide prognostic information. The presence of visible mucosal islands or a colonic diameter of $>5.5 \mathrm{~cm}$ (toxic megacolon) predicts corticosteroid failure in $75 \%$ of patients. ${ }^{10}$ Additionally, small bowel distention $(>3 \mathrm{~cm})$ conveys an increased risk for colectomy during the same admission. ${ }^{19}$

None of these predictors, however, single or combined, is able to accurately predict risk of colectomy in ASUC. Identifying patients at risk thus still remains a problem and should be the topic of future prospective studies.

\section{Challenge 2: Current Treatment Strategies of ASUC are Based on Low Quality Evidence}

Current management of ASUC is not based on highquality evidence with only a few good quality RCTs performed and these are performed on only a limited number of patients. This lack of sound evidence might explain why the evolution of successful management in ASUC are far behind compared to general IBD management.

Using corticosteroids as a medical salvage therapy was investigated by Truelove and Witts as early as 1955. It was one of the first randomized controlled trials and established corticosteroids as the cornerstone for ulcerative colitis management. ${ }^{5}$ In this pivotal study, 210 patients with moderate to severe colitis were randomized to treatment with $100 \mathrm{mg}$ of cortisone or placebo for a period of six weeks. Clinical remission rates were higher in the steroid-treated group compared to the placebo group 
( $41 \%$ versus $16 \%$ ). This was accompanied by a reduction in mortality (24\% versus $7 \%$ ) and an improvement in endoscopic appearance. In a follow-up trial in 1974, 49 patients with severe ulcerative colitis were treated with 5 days of intravenous methylprednisolone achieving remission in $73 \% .{ }^{20}$ In a meta-analysis, Turner et al combined 32 studies between 1974 and 2006 (of which only 5 were RCTs) and found a pooled response rate of $67 \%$ with a colectomy rate of $27 \% .{ }^{21}$ In a retrospective study in 142 ASUC patients, patients responding to IV corticosteroids were shown to have a low 5 -year colectomy risk (9\%) despite high relapse rates $(64 \%){ }^{22}$

Surprisingly, dose-finding studies are curiously missing in ASUC research, hampering therapy optimization. All but three studies in the meta-analyses used higher doses of intravenous corticosteroids ( $>60 \mathrm{mg} /$ day $)$, although a meta-regression showed no correlation between corticosteroid dosing and colectomy rate ${ }^{21}$ Considering therapy duration, one study showed no benefit of extending therapy beyond 7-10 days. ${ }^{23}$ Continuous intravenous administration of corticosteroids was found not to be superior to once daily dosing. ${ }^{24}$ Dose-ranging studies are needed to optimize corticosteroid therapy in ASUC management. Current guidelines recommend using a single IV dose of $60 \mathrm{mg}$ methylprednisolone or hydrocortisone $100 \mathrm{mg}$ every six hours. ${ }^{25,26}$

Calcineurin inhibitors were first investigated for the treatment of ASUC in 1994. In this trial that was terminated prematurely due to ethical reasons, 20 patients with ASUC not responding to corticosteroid therapy were randomized to treatment with IV cyclosporin $(4 \mathrm{mg} / \mathrm{kg})$ or placebo. Eighty-two percent $(9 / 11)$ of patients in the cyclosporin group showed clinical response versus no patients in the placebo group (0/9). ${ }^{27}$ In a single centre, randomized controlled trial 73 patients with ASUC were randomized to treatment with IV cyclosporin $4 \mathrm{mg} / \mathrm{kg}$ or $2 \mathrm{mg} / \mathrm{kg}$ showing similar response (respectively $84 \%$ and $85 \%)$ and colectomy rates ( $13.1 \%$ vs $8.6 \%)$ in both groups. There was no difference in adverse event rate. Oral tacrolimus (target trough level $10-15 \mathrm{ng} / \mathrm{mL}$ ) was investigated in a Japanese RCT enrolling 62 patients with severely active ulcerative colitis with response rates of $50 \%$ vs $13 \%$ in the placebo group. ${ }^{28}$ Current guidelines recommend IV administration of cyclosporin at a dose of $2 \mathrm{mg} /$ $\mathrm{kg}$ /day with target trough levels of $150-250 \mathrm{ng} / \mathrm{mL}$. In the maintenance phase oral cyclosporine is recommended for several months as a bridging therapy $(4 \mathrm{mg} / \mathrm{kg}$, twice daily with a target trough level of 100-200 ng/mL). Patients should be monitored for hypomagnesia, hypocholesterolemia and kidney failure.

Despite these consistent (though based on limited data) findings, use of calcineurin inhibitors in clinical practise was limited by concerns for renal, neurologic, infectious and hypertensive toxicities of cyclosporin, leading clinicians to increasingly turn to anti-TNF in this setting. In a small Swedish-Danish RCT, Järnerot et al randomised 45 patients to placebo or a single infusion of infliximab $5 \mathrm{mg} /$ $\mathrm{kg}$ with $7(7 / 24,29 \%)$ needing a colectomy within three months in the infliximab group versus $14(14 / 21,48 \%$, $\mathrm{p}=0.017)$ in the placebo-treated patients. ${ }^{29}$ Based on these results, 2 RCTs subsequently compared infliximab therapy to cyclosporin for the treatment of ASUC. In the openlabel CYSIF trial, 115 patients were allocated to receive cyclosporin rescue therapy (IV, $2 \mathrm{mg} / \mathrm{kg}$ for 1 week, followed by oral drug until day 98) or infliximab $(5 \mathrm{mg} / \mathrm{kg}$ on week $0,2,6)$. Treatment failure, defined as treatment cessation, colectomy or death, occurred in $35 / 58(60 \%)$ of the cyclosporin treated group vs in $31 / 57$ (54\%) of the infliximab treated patients $(p=0.52)$, showing no significant difference between both treatment regimens at day $98 .{ }^{30}$ A follow-up study showed no difference in colectomy rates at 5 years between both groups. ${ }^{31}$ A second openlabel RCT, the CONSTRUCT study, 270 participants were randomized to cyclosporin $(2 \mathrm{mg} / \mathrm{kg} /$ day IV for 1 week, followed by oral cyclosporin $5.5 \mathrm{mg} / \mathrm{kg}$ for 12 weeks) or infliximab ( $5 \mathrm{mg} / \mathrm{kg}$ at 0,2 and 6 weeks) again showed no difference in efficacy to avoid colectomy between the two treatment regiments (respectively $41 \%$ and $48 \%$, $\mathrm{p}=0.223){ }^{32} \mathrm{~A}$ cost-analysis showed cyclosporin to be more cost-effective than the infliximab-based regimen. In a meta-analysis of 13 non-randomized studies comparing infliximab versus cyclosporin, there was no difference in colectomy rates at three months, but infliximab therapy appeared to be associated with lower rates at 1 year (OR $0.42(0.22-0.83)){ }^{33}$ In a large, retrospective Spanish cohort (ENEIDA) 740 subjects with ASUC were included over a period of 24 years. Despite its methodological issues, this large cohort again showed no difference in colectomy rate between cyclosporin and infliximab therapy (respectively $19.6 \%$ and $23.6 \%, p=0.57$ at 1 year) with severe adverse events and infection being more common in the infliximab group. ${ }^{34,35}$ However, a recent prospective cohort study in 55 ASUC patients showed higher endoscopic remission rates in infliximab treated patients compared to patients treated with cyclosporine $(73 \%$ vs $25 \%){ }^{36}$ Additionally, a recent retrospective study in 296 
Korean ASUC patients treated showed better colectomy rates with infliximab then previously described (eg, 6.9\% at 3 months and $18.1 \%$ at a mean follow-up of 69 months). ${ }^{37}$ Although data about the use of biosimilars in ASUC is limited, a retrospective study in 21 patients suggests similar remission rates. ${ }^{38}$

Sequential use of ciclosporin and infliximab has been reported, but studies are generally of low quality, produced conflicting results and do not authorise its use in standard clinical practise. However, a systematic review published in 2015 and combining 10 low-quality studies (314 participants) showed pooled response rates of $62.4 \%$ (95\% CI $57-68.7 \%$ ) and colectomy rates at three months in $28.3 \%$ of cases (95\% CI 21.7-34.5\%). Serious infections occurred in $6.7 \%$ (95\% CI 3.6-9.8\%) and death in $1 \%$ (95\% CI $0-2.1 \%$ ) reminding clinicians to be extremely cautious before applying sequential therapy in ASUC. ${ }^{39}$ In a more recent retrospective study of 40 ASUC patients failing infliximab therapy treated with cyclosporin achieved clinical remission in $60 \%$ of cases. Adverse events occurred in 16 patients $(40 \%)$ but none were serious enough to discontinue the drug. ${ }^{40}$ Given the increased risk of opportunistic infections, prophylaxis for pneumocystis jirovecii should be considered in these patients. ${ }^{25}$

Overall, current recommendations for the treatment of ASUC are not based on a sound body of evidence, and additional studies are required.

\section{Challenge 3: Despite Recent Advances in IBD Therapy, Colectomy Rates for ASUC Have Decreased but Remain High}

Medical therapy for ASUC has had an important impact on the ASUC mortality rate over the past decades. Historically, ASUC has been a particularly deadly condition with an in-hospital mortality ranging up to $28 \%$ with another $25 \%$ of patients dying within the following 10 years. ${ }^{41}$ The introduction of corticosteroids in the early 1950s caused a significant drop in the overall mortality of UC with only $7 \%$ of patients succumbing to the disease, but prognosis of patients with ASUC only really improved with the introduction of the "Oxford regimen". ${ }^{20,41}$ In the 1970s, implementation of this protocol consisting of early recognition of the severity of colitis, high-dose intravenous corticosteroids for 5-7 days and early deviation to colectomy for patients who did not respond to medical therapy reduced ASUC mortality from $30 \%$ to $<2 \%{ }^{20,42}$ Shortterm colectomy rates with this protocol, however, were still at $30 \%$. As emergency colectomies are associated with high morbidity, health-care costs and has a negative impact on the quality of life, attempts were made to reduce the need for colectomy. ${ }^{43,44}$ In the eighties, the length of corticosteroid therapy was increased to 10 days but this failed to reduce colectomy rates. ${ }^{23,45}$ Rescue protocols using immunosuppressive medication were developed in the nineties and appeared successful on the short term but did not reduce the colectomy rate in the long run. ${ }^{43}$ Although immediate remission rates with cyclosporin, for instance, reach $70-80 \%$, about $50 \%$ of the initial responders will still require a colectomy in the long term. ${ }^{27,46,47}$ Infliximab-based rescue therapy has similar success in avoiding emergency surgery, but long-term colectomy rates still remain around $20 \%{ }^{43}$ So despite all the advances in medical IBD therapy, the overall need for colectomy in ASUC still remains relatively unchanged, although mortality rates have decreased significantly.

\section{Solutions Towards a Better ASUC Management in the Future}

Despite the fact that numerous challenges remain to be solved in ASUC management, current evidence does already provide several solutions to improve our current care of patients with ASUC. How we can integrate these in clinical practise is represented in Figure 1 and Box $1 .{ }^{25}$

\section{Early Recognition, Close Monitoring and Timely Re-Assessment of ASUC Treatment are Primordial}

Any patient meeting the criteria for severe disease should be recognized promptly and admitted in the hospital. Stool cultures for enteric pathogens and Clostridium difficile should be taken at the earliest possibility but results should not be awaited before rapid IV corticosteroid therapy. Flexible unprepared sigmoidoscopy with minimal air insufflation should be performed within 24 hours of

\section{Box I Tips to Improve Your Care of ASUC Patients}

I. Early recognition of patients at risk for ASUC

2. Multidisciplinary approach early on in the treatment process

3. Close monitoring of the patients with optimal timing of salvage therapy

4. Correct dosing of the salvage therapy

5. Focus on nutritional support

6. Do not forget thromboprophylaxis 


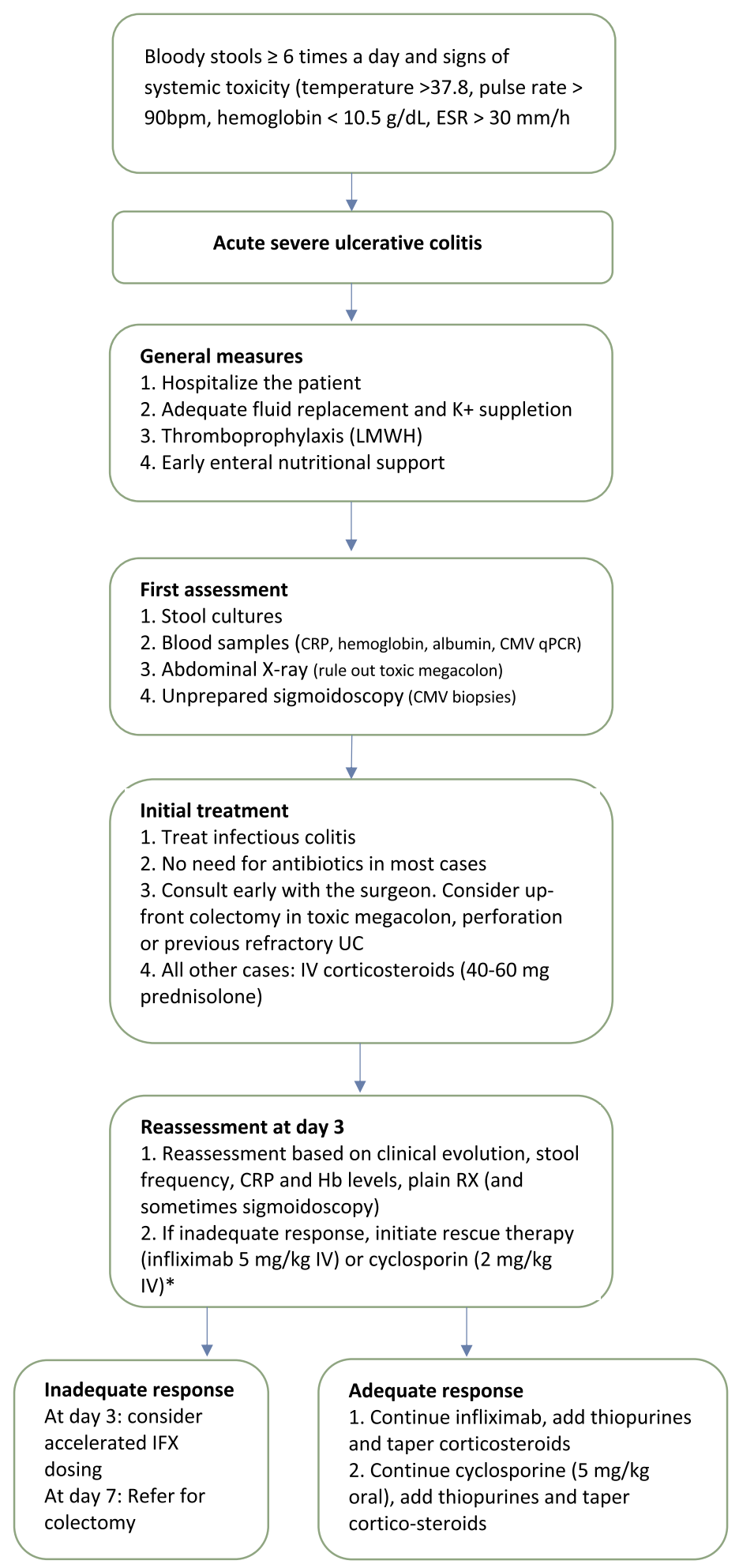

*combination with vedolizumab might be considered older than 50 years with anaemia, low albumin, UCEIS > 7 or Mayo 3.

Figure I Treatment algorithm for acute severe ulcerative colitis. Adapted with permission from Hindryckx P, Jairath V, D'Haens G. Acute severe ulcerative colitis:from pathophysiology to clinical management. Nat Rev GastroenterolHepatol. 2016;13(11):654-664. Copyright @ 2016, Nature Publishing Group, a division of Macmillan Publishers Limited. All Rights Reserved. ${ }^{3}$ 
admission to confirm diagnosis and exclude a superimposed infection with the cytomegalovirus (CMV). ${ }^{3,8}$

Following initiation of corticosteroid therapy patients should be closely monitored with daily blood works, clinical examination and serial abdominal films as clinically indicated. Positive stool cultures should prompt treatment with antibiotics, presence of a significant amount CMV inclusions on colonic biopsy are an indication for ganciclovir treatment. Formal re-assessment is performed between days 3 and 5.,8 As discussed above, current evidence does not allow for a singular recommendation. Failure of corticosteroid therapy is therefore based on a clinical, biochemical and radiological assessment. Several indices such as stool frequency, CRP and albumin levels and colonic dilatation on plain radiography can be used as described above.

\section{Optimal ASUC Care is Multidisciplinary in Nature}

ASUC management requires early liaison with other medical specialities from the start of the admission with the multidisciplinary team consisting of a gastroenterologist specialised in IBD, an abdominal surgeon, a radiologist, the IBD nurse and a nutritionist.

Although medical therapy remains first line, colectomy can be considered as a "definite" treatment for ASUC and a colorectal surgeon should be consulted from first admission onwards. An urgent colectomy is indicated in case of colonic perforation, toxic megacolon, refractory bleeding or failure of medical rescue therapy. ${ }^{48,49}$ Direct referral for colectomy before initiating rescue therapy can also be considered in patients who were previously proven to be refractory to thiopurine or anti-TNF therapy. ${ }^{49}$ Adequate timing of the colectomy is important as delayed referral is associated with increased postoperative complications and should therefore be considered after failure of medical rescue therapy with anti-TNF or cyclosporin. ${ }^{48,49}$ In a retrospective study in the UK examining $>23.000$ IBD-related hospitalization and over 5000 colectomies between 1998 and 2003, three-year colectomy mortality rates were indeed significantly lower in an elective setting versus when performed in emergency $(3.7 \%$ versus $13.7 \%, \mathrm{p}<0.001) .{ }^{50}$ Proctocolectomy with ileal pouch-anal anastomosis (IPAA) is the preferred technique used in the surgical management of ASUC and is typically performed in three stages. ${ }^{51}$ In the acute setting, a subtotal colectomy with ileostomy is performed with the rectum left in place, either with the remaining colon being brought outwards as a mucous fistula or closed into the subcutaneous fat. This procedure is safe in the acute setting and removes the inflammatory burden allowing recovery of the patient. In a second restorative phase, performed preferably after three to six months, an ileal loop pouch is formed with defunctioning loop ileostomy. ${ }^{48,49,51}$ Only in the third and last phase, the loop ileostomy is closed. A laparoscopic approach is to be preferred when feasible as this is as safe and effective but reduces the in-hospital stay, time to stoma function and is limits the formation of intestinal adhesions compared to open surgery. ${ }^{52,53}$ Surgery in the setting of ASUC is preferably performed in high-volume centres as this improves clinical outcomes and mortality. $8,48,49,52$

Discussing the timing and (dis)advantages of surgery early on with the patient is important and requires not only the colorectal surgeon but an early intervention of the stoma nurse. Despite offering the prospect of a restored bowel function, IPAA in itself has a significant impact on functionality and quality of life. Frequently occurring complications such as leakage, sexual dysfunction, soiling and the occurrence of inflammatory disorders of the pouch (pouchitis) in up to $50 \%$ of IPAA patients should be discussed upfront. Importantly, ileal pouch-anal anastomosis has profound effects on female fertility in a population often within the child-bearing age, although laparoscopic approaches tend to have less severe effects, presumably due to less intra-abdominal adhesions. ${ }^{54,55}$

Liaison with the nutrition team from the beginning of the treatment is equally as important. High-dose corticosteroids and malnutrition are important predictors of postoperative complications. Early optimisation of the nutritional status of ASUC patients is thus primordial, and enteral nutrition is usually preferred unless in the setting of toxic megacolon or paralytic ileus. In a prospective randomized trial, 42 ASUC patients were randomized to enteral feeding or total parenteral nutrition, with enteral feeding having a more profound effect on albumin levels, was associated with less nutrition-related complication and less postoperative complications. ${ }^{56}$ Another randomized trial in 47 with severe colitis, bowel rest was not found to influence resection or mortality rates. ${ }^{57}$

\section{Optimal Dose Targeting is Primordial}

Several lines of evidence suggest that conventional weight-based dosing of infliximab salvage therapy might be insufficient in ASUC. The severe intestinal inflammation is associated with an important intestinal loss of protein resulting in hypoalbuminaemia but also a rapid 
clearance of infliximab in the faeces. ${ }^{58}$ Additionally, high concentrations of mucosal metalloproteinases, associated with inflammation, lead to degradation and inactivation of anti-TNF antibodies. ${ }^{59,60}$

In a pharmacokinetic study, Brandse et al showed that patients with a faster intestinal clearance of infliximab were at risk for worse clinical outcomes and had an increased chance of infusion-related reactions compared to patients with a normal drug clearance. Drug clearance seemed to be highest in the group of patients with higher CRP levels $(>50 \mathrm{mg} / \mathrm{L}) .{ }^{59}$ In a retrospective analysis of 50 patients hospitalized for ASUC an accelerated dosing strategy of infliximab ( 3 induction doses of infliximab within 3 weeks versus the normal induction strategy of 0.2 and 6 weeks) was associated with a lower colectomy rate ( $7 \%$ versus $40 \%$, respectively, $\mathrm{p}=0.039) .{ }^{61}$ However, in another multicentre, retrospective study including 213 patients with steroid refractory ASUC no difference was found between normal and accelerated dosing strategy, although dosing regimens including a higher induction dose of infliximab $(10 \mathrm{mg} / \mathrm{kg})$ were associated with a lower rate of colectomy. ${ }^{62}$

Prospective studies investigating the effects of dose optimisation in ASUC are currently ongoing. In the TITRATE study in the Netherlands patients with ASUC are randomized to conventional infliximab induction versus a target trough level-based induction protocol (NCT03937609).

Awaiting results of these formal prospective studies, many centres, however, currently advocate the use of accelerated or higher initial dosing regimens. ${ }^{3}$ CRP levels might be useful to determine which patients need higher infliximab dosing. A commonly used strategy includes augmenting the dose when serum CRP levels do not drop below $50 \mathrm{mg} / \mathrm{L}$ after 3 days, although this is not supported by prospective studies. ${ }^{3,63}$ Patient with low serum albumin levels $(<35 \mathrm{~g} / \mathrm{L})$ should especially be considered for accelerated dosing. ${ }^{25}$

Patients not responding to rescue therapy with infliximab or cyclosporin by day 7 or that develop serious complications earlier (eg, toxic megacolon or perforation) should be referred for colectomy. ${ }^{25}$

\section{New Molecules Might Change the Approach to ASUC in the Future}

In the last decade, many new options for treating IBD have become available. As some of these molecules can induce a rapid remission, they might be useful in the management of ASUC although data are still limited. ${ }^{64}$
Tofacitinib is a small molecule that inhibits the Janus kinases (JAK) 1.2 and 3 which is a central molecule in pro-inflammatory cytokine production and response. In the OCTAVE trials tofacitinib was shown to induce remission more often than placebo in patients with moderate-tosevere ulcerative colitis that failed initial anti-TNF therapy. ${ }^{65}$ Post-hoc analysis of the trials moreover shows that induction of remission is particularly fast with these JAK inhibitors and occurs over a three-day period, making it a viable solution for treating ASUC. ${ }^{66}$ Data with tofacitinib in ASUC management are still limited, however. In a case series of 4 patients with ASUC, 3 out of 4 patients achieved clinical remission and colectomy was avoided in $50 \% .{ }^{67}$ In another case series of again only 4 patients all patients achieved remission, and no one had to undergo colectomy. ${ }^{68}$ In a recent case series of 5 ASUC patients who had failed anti-TNF therapy, 3 improved under tofacitinib therapy while 2 eventually had to undergo a colectomy. ${ }^{69}$ Further prospective studies are needed.

Vedolizumab is selective antagonist of the $\alpha 4 \beta 7$ integrin and prevents local leukocyte trafficking to the gut. However, onset of remission is slow and is probably less suited for ASUC despite good responses in moderate-to-severe ulcerative colitis (GEMINI 1). ${ }^{70}$ No trials have thus investigated the effects of vedolizumab in the setting of ASUC. ${ }^{64}$ However, in several retrospective series, patients with ASUC were treated with a combination of calcineurin inhibitors and vedolizumab. In a series of 39 patients performed by the GETAID, 39 patients (of which 36 had previously failed anti-TNF therapy) received a calcineurin inhibitor as induction therapy alongside vedolizumab as maintenance. ${ }^{71}$ At 12 months, 68\% survived without undergoing a colectomy. In another retrospective series of 71 patients with ASUC, 55\% was colectomy-free at two years following induction. ${ }^{72}$ Combining cyclosporin with vedolizumab might be a therapeutic option in older patients with comorbidities.

The recent UNIFI trials show that ustekinumab, an anti-IL12/23 antagonist, induces clinical remission in moderate-to-severe colitis more often than placebo (respectively $15 \%$ vs $5 \%$ ). ${ }^{72}$ Despite the rapid onset of remission, no trials are specifically investigating the use of ustekinumab in ASUC.

At the moment only one clinical trial is currently ongoing, investigating the effects of new molecules in ASUC. ${ }^{73}$ In the UK-based IASO trial, patients with ASUC are being randomized to placebo treatment or treatment with anti-IL1 treatment (Anakinra) as an adjuvant to corticosteroid therapy. ${ }^{73}$ 


\section{Conclusions}

ASUC remains a challenging condition to treat for physicians, especially in centres with low exposure rates to this condition. Additionally, important knowledge gaps still remain, and dedicated studies are necessary to answer them. Current evidence does provide us with a couple of solutions to improve our care of ASUC patients and limit the number of colectomies. First of all, emphasis should be on an early recognition of the disease, close follow-up of admitted patients and timely initiation of salvage therapy. Surgeons and nutritional therapists should be included in the multidisciplinary team from the very start of the admission. Salvage therapies should be administrated in an optimal dose, although studies are currently still ongoing on which strategy is to be preferred. Lastly, several new molecules have become available that might change the way we treat ASUC patients in the near future.

\section{Author Contributions}

All authors made substantial contributions to conception and design, acquisition of data, or analysis and interpretation of data; took part in drafting the article or revising it critically for important intellectual content; agreed on the journal to which the article will be submitted; gave final approval of the version to be published; and agree to be accountable for all aspects of the work.

\section{Disclosure}

Triana Lobaton reports grants and personal fees from Janssen, Biogen, grants from Abbvie, Takeda, and Mylan, and personal fees from Ferring, outside the submitted work. The authors report no other potential conflicts of interest for this work.

\section{References}

1. Ordás I, Eckmann L, Talamini M, Baumgart DC, Sandborn WJ. Ulcerative colitis. Lancet. 2012;380(9853):1606-1619. doi:10.1016/ S0140-6736(12)60150-0

2. Molodecky NA, Soon IS, Rabi DM, et al. Increasing incidence and prevalence of the inflammatory bowel diseases with time, based on systematic review. Gastroenterology. 2012;142(1):46-54.e42. doi:10.1053/j.gastro.2011.10.001

3. Hindryckx P, Jairath V, D'Haens G. Acute severe ulcerative colitis: from pathophysiology to clinical management. Nat Rev Gastroenterol Hepatol. 2016;13(11):654-664. doi:10.1038/nrgastro.2016.116

4. Kappelman MD, Rifas-Shiman SL, Porter C, et al. Direct health care costs of Crohn's disease and ulcerative colitis in united states children and adults. Gastroenterology. 2008;135(6):1907-1913. doi:10.1053/j. gastro.2008.09.012

5. Truelove SC, Witts LJ. Cortisone in ulcerative colitis final report on a therapeutic trial. Br Med J. 1955;2(4947):1041-1048. doi:10.1136/ bmj.2.4947.1041
6. Mak WY, Zhao M, Ng SC, Burisch J. The epidemiology of inflammatory bowel disease: East meets west. J Gastroenterol Hepatol. 2019;35:3. doi:10.1111/jgh.14872

7. Hedin CRH, Vavricka SR, Stagg AJ, et al. Predicting outcomes to optimize disease management in inflammatory bowel diseases. J Crohns Colitis. 2016;13(5):541-554. doi:10.1093/ECCO-JCC

8. Gisbert JP, Chaparro M. Acute severe ulcerative colitis: state of the art treatment. Best Pract Res Clin Gastroenterol. 2018;32-33:59-69. doi:10.1016/j.bpg.2018.05.007

9. Moore AC, Bressler B. Acute severe ulcerative colitis: the oxford criteria no longer predict in-hospital colectomy rates. Dig Dis Sci. 2020;65:576-580. doi:10.1007/s10620-019-05668-6

10. Lennard Jones JE, Ritchie JK, Hilder W, Spicer CC. Assessment of severity in colitis: a preliminary study. Gut. 1975;16(8):579-584. doi:10.1136/gut.16.8.579

11. Benazzato L, D'Incà R, Grigoletto F, et al. Prognosis of severe attacks in ulcerative colitis: effect of intensive medical treatment. Dig Liver Dis. 2004;36(7):461-466. doi:10.1016/j.dld. 2003.12.017

12. Grant RK, Jones G-R, Plevris N, et al. The ACE (Albumin, CRP and Endoscopy) index in acute colitis: a simple clinical index on admission that predicts outcome in patients with acute ulcerative colitis. Inflamm Bowel Dis. 2020. doi:10.1093/ibd/izaa088

13. Ho GT, Lee HM, Brydon G, et al. Fecal calprotectin predicts the clinical course of acute severe ulcerative colitis. Am J Gastroenterol. 2009;104(3):673-678. doi:10.1038/ajg.2008.119

14. Ma R, Meng R, Zhang X, Sun Z, Lei Y. Correlation between fecal calprotectin, ulcerative colitis endoscopic index of severity and clinical outcome in patients with acute severe colitis. Exp Ther Med. 2020;20(2):1498-1504. doi:10.3892/etm.2020.8861

15. Turner D, Mack D, Leleiko N, et al. Severe pediatric ulcerative colitis: a prospective multicenter study of outcomes and predictors of response. Gastroenterology. 2010;138(7):2282-2291. doi:10.1053/ j.gastro.2010.02.047

16. Wu H, Wei J, Li J, et al. Serum procalcitonin as a potential early predictor of short-term outcomes in acute severe ulcerative colitis. Dig Dis Sci. 2019;64(11):3263-3273. doi:10.1007/s10620-0185446-0

17. Morilla I, Uzzan M, Laharie D, et al. Colonic MicroRNA profiles, identified by a deep learning algorithm, that predict responses to therapy of patients with acute severe ulcerative colitis. Clin Gastroenterol Hepatol. 2019;17(5):905-913. doi:10.1016/j. cgh.2018.08.068

18. Corte C, Fernandopulle N, Catuneanu AM, et al. Association between the ulcerative colitis endoscopic index of severity (UCEIS) and outcomes in acute severe ulcerative colitis. J Crohns Colitis. 2015;9(5):376-381. doi:10.1093/ecco-jcc/jjv047

19. Chew CN, Nolan DJ, Jewell DP. Small bowel gas in severe ulcerative colitis. Gut. 1991;32(12):1535-1537. doi:10.1136/ gut.32.12.1535

20. Truelove SC, Jewell DP. Intensive intravenous regimen for severe attacks of ulcerative colitis. Lancet. 1974;303(7866):1067-1070. doi:10.1016/S0140-6736(74)90552-2

21. Turner D, Walsh CM, Steinhart AH, Griffiths AM. Response to corticosteroids in severe ulcerative colitis: a systematic review of the literature and a meta-regression. Clin Gastroenterol Hepatol. 2007;5(1):103-110. doi:10.1016/j.cgh.2006.09.033

22. Salameh R, Kirchgesner J, Allez M, et al. Long-term outcome of patients with acute severe ulcerative colitis responding to intravenous steroids. Aliment Pharmacol Ther. 2020;51(11):1096-1104. doi:10.1111/apt.15751

23. Meyers S, Lerer PK, Feuer EJ, Johnson JW, Janowitz HD. Predicting the outcome of corticoid therapy for acute ulcerative colitis: results of a prospective, randomized, double-blind clinical trial. J Clin Gastroenterol. 1987;9(1):50-54. doi:10.1097/00004836-19870200000013 
24. Bossa F, Fiorella S, Caruso N, et al. Continuous infusion versus bolus administration of steroids in severe attacks of ulcerative colitis: a randomized, double-blind trial. Am J Gastroenterol. 2007;102 (3):601-608. doi:10.1111/j.1572-0241.2006.01007.x

25. Lamb CA, Kennedy NA, Raine T, et al. British society of gastroenterology consensus guidelines on the management of inflammatory bowel disease in adults. Gut. 2019;68(Suppl 3):s1-s106. doi:10.1136/ gutjnl-2019-318484

26. Rönnblom A, Karlbom U. Acute severe attacks of ulcerative colitis in a population-based cohort: epidemiology, treatment and outcome. Scand J Gastroenterol. 2020;55(5):555-559. doi:10.1080/ 00365521.2020 .1757143

27. Lichtiger S, Present DH, Kornbluth A, et al. Cyclosporine in severe ulcerative colitis refractory to steroid therapy. $N$ Engl J Med. 1994;330(26):1841-1845. doi:10.1056/NEJM199406303302601

28. Ogata H, Kato J, Hirai F, et al. Double-blind, placebo-controlled trial of oral tacrolimus (FK506) in the management of hospitalized patients with steroid-refractory ulcerative colitis. Inflamm Bowel Dis. 2012;18(5):803-808. doi:10.1002/ibd.21853

29. Järnerot G, Hertervig E, Friis-Liby I, et al. Infliximab as rescue therapy in severe to moderately severe ulcerative colitis: a randomized, placebo-controlled study. Gastroenterology. 2005;128 (7):1805-1811. doi:10.1053/j.gastro.2005.03.003

30. Laharie D, Bourreille A, Branche J, et al. Ciclosporin versus infliximab in patients with severe ulcerative colitis refractory to intravenous steroids: a parallel, open-label randomised controlled trial. Lancet. 2012;380 (9857):1909-1915. doi:10.1016/S0140-6736(12)61084-8

31. Laharie D, Bourreille A, Branche J, et al. Long-term outcome of patients with steroidrefractory acute severe UC treated with ciclosporin or infliximab. Gut. 2018;67:237-243. doi:10.1136/gutjnl-2016-313060

32. Williams JG, Alam MF, Alrubaiy L, et al. Infliximab versus ciclosporin for steroid-resistant acute severe ulcerative colitis (CONSTRUCT): a mixed methods, open-label, pragmatic randomised trial. Lancet Gastroenterol Hepatol. 2016;1(1):15-24. doi:10.1016/S2468-1253(16)30003-6

33. Narula N, Marshall JK, Colombel JF, et al. Systematic review and meta-analysis: infliximab or cyclosporine as rescue therapy in patients with severe ulcerative colitis refractory to steroids. $\mathrm{Am}$ J Gastroenterol. 2016;111(4):477-491. doi:10.1038/ajg.2016.7

34. Bernstein CN, Kornbluth A. Yes, we are still talking about cylosporin vs. infliximab in steroid resistant acute severe ulcerative colitis. Am J Gastroenterol. 2017;112(11):1719-1721. doi:10.1038/ajg.2017.282

35. Ordás I, Domènech $\mathrm{E}$, Mañosa $\mathrm{M}$, et al. Long-term efficacy and safety of cyclosporine in a cohort of steroid-refractory acute severe ulcerative colitis patients from the ENEIDA registry (1989-2013): a nationwide multicenter study. Am J Gastroenterol. 2017;112 (11):1709-1718. doi:10.1038/ajg.2017.180

36. Laharie D, Bourreille A, Branche J, et al. Evolution of endoscopic lesions in steroid-refractory acute severe ulcerative colitis responding to infliximab or cyclosporine. Clin Gastroenterol Hepatol. 2020. doi:10.1016/j.cgh.2020.08.001

37. Oh SJ, Shin GY, Soh H, et al. Long-term outcomes of infliximab in a real-world multicenter cohort of patients with acute severe ulcerative colitis. Intest Res. 2020. doi:10.5217/ir.2020.00039

38. Ollech JE, Normatov I, Peleg N, et al. Efficacy of biosimilar infliximab CT-P13 among inpatients with severe steroid-refractory colitis. Int J Colorectal Dis. 2020;35(11):2113-2116. doi:10.1007/s00384020-03703-x

39. Narula N, Fine M, Colombel JF, Marshall JK, Reinisch W. Systematic review: sequential rescue therapy in severe ulcerative colitis: do the benefits outweigh the risks? Inflamm Bowel Dis. 2015;21(7):1683-1694. doi:10.1097/MIB.0000000000000350

40. Weisshof R, Ollech JE, El Jurdi K, et al. Ciclosporin therapy after infliximab failure in hospitalized patients with acute severe colitis is effective and safe. J Crohns Colitis. 2019;13(9):1105-1110. doi:10.1093/ecco-jcc/jjz032
41. Lee ECG, Truelove SC. Proctocolectomy for ulcerative colitis. World J Surg. 1980;4(2):195-201. doi:10.1007/BF02393575

42. Dong C, Metzger M, Holsbø E, Perduca V, Carbonnel F. Systematic review with meta-analysis: mortality in acute severe ulcerative colitis. Aliment Pharmacol Ther. 2020;51(1):8-33. doi:10.1111/apt.15592

43. Aratari A, Papi C, Clemente V, et al. Colectomy rate in acute severe ulcerative colitis in the infliximab era. Dig Liver Dis. 2008;40 (10):821-826. doi:10.1016/j.dld.2008.03.014

44. Alves A, Panis Y, Bouhnik Y, Maylin V, Lavergne-Slove A, Valleur P. Subtotal colectomy for severe acute colitis: a 20-year experience of a tertiary care center with an aggressive and early surgical policy. J Am Coll Surg. 2003;197(3):379-385. doi:10.1016/ S1072-7515(03)00434-4

45. Järnerot G, Rolny P, Sandberg-Gertzén H. Intensive intravenous treatment of ulcerative colitis. Gastroenterology. 1985;89 (5):1005-1013. doi:10.1016/0016-5085(85)90201-X

46. Moskovitz DN, van Assche G, Maenhout B, et al. Incidence of colectomy during long-term follow-up after cyclosporine-induced remission of severe ulcerative colitis. Clin Gastroenterol Hepatol. 2006;4(6):760-765. doi:10.1016/j.cgh.2006.04.001

47. Campbell S, Travis S, Jewell D. Ciclosporin use in acute ulcerative colitis: a long-term experience. Eur J Gastroenterol Hepatol. 2005;17 (1):79-84. doi:10.1097/00042737-200501000-00016

48. Harbord M, Eliakim R, Bettenworth D, et al. Third European evidence-based consensus on diagnosis and management of ulcerative colitis. Part 2: current management. J Crohns Colitis. 2017;11 (7):769-784. doi:10.1093/ecco-jcc/jjx009

49. Feuerstein JD, Isaacs KL, Schneider Y, Siddique SM, Falck-Ytter Y, Singh S. AGA clinical practice guidelines on the management of moderate to severe ulcerative colitis. Gastroenterology. 2020;158:1450-1461. doi:10.1053/j.gastro.2020.01.006

50. Roberts SE, Williams JG, Yeates D, Goldacre MJ. Mortality in patients with and without colectomy admitted to hospital for ulcerative colitis and Crohn's disease: record linkage studies. $\mathrm{Br}$ Med J. 2007;335(7628):1033-1036. doi:10.1136/bmj.39345.714039.55

51. Adamina M, Angriman I, Bemelman WA, et al. European evidence based consensus on surgery for ulcerative colitis. J Crohns Colitis. 2015;9(1):4-25. doi:10.1016/j.crohns.2014.08.012

52. Chen JH, Andrews JM, Kariyawasam V, et al. Review article: acute severe ulcerative colitis - Evidence-based consensus statements. Aliment Pharmacol Ther. 2016;44(2):127-144. doi:10.1111/ apt. 13670

53. Bartels SAL, Vlug MS, Henneman D, Ponsioen CY, Tanis PJ, Bemelman WA. Less adhesiolysis and hernia repair during completion proctocolectomy after laparoscopic emergency colectomy for ulcerative colitis. Surg Endosc. 2012;26(2):368-373. doi:10.1007/ s00464-011-1880-1

54. Ørding Olsen K, Juul S, Berndtsson I, Öresland T. Ulcerative colitis: female fecundity before diagnosis, during disease, and after surgery compared with a population sample. Gastroenterology. 2002;122 (1):15-19. doi:10.1053/gast.2002.30345

55. Bartels SAL, D'Hoore A, Cuesta MA, Bensdorp AJ, Lucas C, Bemelman WA. Significantly increased pregnancy rates after laparoscopic restorative proctocolectomy: a cross-sectional study. Ann Surg. 2012;256(6):1045-1048. doi:10.1097/SLA.0b013e318250caa9

56. González-Huix F, Fernández-Bañares F, Esteve-Comas M, et al. Enteral versus parenteral nutrition as adjunct therapy in acute ulcerative colitis. Am J Gastroenterol. 1993;88(2):227-232. doi:10.1111/ j.1572-0241.1993.tb07510.x

57. McIntyre PB, Powell-Tuck J, Wood SR, et al. Controlled trial of bowel rest in the treatment of severe acute colitis. Gut. 1986;27 (5):481-485. doi:10.1136/gut.27.5.481

58. Brandse JF, van den Brink GR, Wildenberg ME, et al. Loss of infliximab into feces is associated with lack of response to therapy in patients with severe ulcerative colitis. Gastroenterology. 2015;149 (2):350-355.e2. doi:10.1053/j.gastro.2015.04.016 
59. Brandse JF, Mathôt RA, van der Kleij D, et al. Pharmacokinetic features and presence of antidrug antibodies associate with response to infliximab induction therapy in patients with moderate to severe ulcerative colitis. Clin Gastroenterol Hepatol. 2016;14(2):251-258. e2. doi:10.1016/j.cgh.2015.10.029

60. Dotan I, Ron Y, Yanai H, et al. Patient factors that increase infliximab clearance and shorten half-life in inflammatory bowel disease: a population pharmacokinetic study. Inflamm Bowel Dis. 2014;20 (12):2247-2259. doi:10.1097/MIB.0000000000000212

61. Gibson DJ, Heetun ZS, Redmond CE, et al. An accelerated infliximab induction regimen reduces the need for early colectomy in patients with acute severe ulcerative colitis. Clin Gastroenterol Hepatol. 2015;13(2):330-335.e1. doi:10.1016/j.cgh.2014.07.041

62. Nalagatla N, Falloon K, Tran G, et al. Effect of accelerated infliximab induction on short- and long-term outcomes of acute severe ulcerative colitis: a retrospective multicenter study and meta-analysis. Clin Gastroenterol Hepatol. 2019;17(3):502-509.e1. doi:10.1016/j. cgh.2018.06.031

63. Rosen MJ, Minar P, Vinks AA. Review article: applying pharmacokinetics to optimise dosing of anti-TNF biologics in acute severe ulcerative colitis. Aliment Pharmacol Ther. 2015;41(11):1094-1103. doi:10.1111/apt.13175

64. Verdon C, Bessissow T, Lakatos PL. Management of acute severe colitis in the era of biologicals and small molecules. J Clin Med. 2019;8(12):2169. doi:10.3390/jcm8122169

65. Sandborn WJ, Su C, Sands BE, et al. Tofacitinib as induction and maintenance therapy for ulcerative colitis. $N$ Engl J Med. 2017;376 (18):1723-1736. doi:10.1056/NEJMoa1606910

66. Hanauer S, Panaccione R, Danese S, et al. Tofacitinib induction therapy reduces symptoms within 3 days for patients with ulcerative colitis. Clin Gastroenterol Hepatol. 2019;17(1):139-147. doi:10.1016/j.cgh.2018.07.009
67. Berinstein JA, Steiner CA, Regal RE, et al. Efficacy of induction therapy with high-intensity tofacitinib in 4 patients with acute severe ulcerative colitis. Clin Gastroenterol Hepatol. 2019;17(5):988-990. e1. doi:10.1016/j.cgh.2018.11.022

68. Kotwani P, Terdiman J, Lewin S. Tofacitinib for rescue therapy in acute severe ulcerative colitis: a real-world experience. J Crohns Colitis. 2020;14(7):1026-1028. doi:10.1093/ecco-jcc/jjaa018

69. Honap S, Pavlidis P, Ray S, et al. Tofacitinib in acute severe ulcerative colitis - a real-world tertiary center experience. Inflamm Bowel Dis. 2020;26(11). doi:10.1093/ibd/izaa157

70. Feagan BG, Rutgeerts P, Sands BE, et al. Vedolizumab as induction and maintenance therapy for ulcerative colitis. $N$ Engl J Med. 2013;369(8):699-710. doi:10.1056/NEJMoa1215734

71. Ollech JE, Dwadasi S, Rai V, et al. Efficacy and safety of induction therapy with calcineurin inhibitors followed by vedolizumab maintenance in 71 patients with severe steroid-refractory ulcerative colitis. Aliment Pharmacol Ther. 2019;51(6):637-643. doi:10.1111/apt.15616

72. Sands BE, Sandborn WJ, Panaccione R, et al. Ustekinumab as induction and maintenance therapy for ulcerative colitis. $N$ Engl J Med. 2019;381(13):1201-1214. doi:10.1056/NEJMoa1900750

73. Thomas MG, Bayliss C, Bond S, et al. Trial summary and protocol for a phase II randomised placebo-controlled double-blinded trial of Interleukin 1 blockade in acute severe colitis: the IASO trial. BMJ Open. 2019;9(2):e023765. doi:10.1136/bmjopen-2018-023765
Clinical and Experimental Gastroenterology

\section{Publish your work in this journal}

Clinical and Experimental Gastroenterology is an international, peerreviewed, open access, online journal publishing original research, reports, editorials, reviews and commentaries on all aspects of gastroenterology in the clinic and laboratory. This journal is indexed on American Chemical Society's Chemical Abstracts Service (CAS)

\section{Dovepress}

The manuscript management system is completely online and includes a very quick and fair peer-review system, which is all easy to use. Visit http://www.dovepress.com/testimonials.php to read real quotes from published authors. 